\title{
Adult rat liver cells transdifferentiated with lentiviral IPF1 vectors reverse diabetes in mice: an ex vivo gene therapy approach
}

\author{
A. Fodor • C. Harel • L. Fodor • M. Armoni • P. Salmon • \\ D. Trono • E. Karnieli
}

Received: 17 July 2006 / Accepted: 1 September 2006 / Published online: 28 November 2006

(C) Springer-Verlag 2006

\author{
Abstract \\ Aims/hypothesis We examined a clinical model of ex vivo \\ transdifferentiation of primary adult hepatocytes to insulin- \\ secreting cells for the treatment of type 1 diabetes. \\ Materials and methods Isolated rat hepatocytes were \\ transduced in primary culture with a human lentivirus \\ containing pancreatic duodenal homeobox 1 ( $P D X 1$, now \\ known as insulin promoter factor 1, homeodomain tran- \\ scription factor [IPF1]). Insulin expression and secretion of \\ Electronic supplementary material Supplementary material is \\ available in the online version of this article at http://dx.doi.org/ \\ $10.1007 / \mathrm{s} 00125-006-0509-8$ and is accessible to authorised users. \\ A. Fodor $\cdot$ C. Harel $\cdot$ M. Armoni $\cdot$ E. Karnieli $(\bowtie)$ \\ The Institute of Endocrinology, Diabetes and Metabolism, \\ Rambam Medical Center, \\ P.O. Box 9602, Haifa 31096, Israel \\ e-mail: eddy@tx.technion.ac.il \\ A. Fodor $\cdot$ C. Harel $\cdot$ M. Armoni $\cdot$ E. Karnieli \\ The RB Rappaport Faculty of Medicine, \\ Technion Israel Institute of Technology, \\ Haifa, Israel \\ L. Fodor \\ Department of Plastic Surgery, \\ Rambam Medical Center, \\ Haifa, Israel \\ P. Salmon \\ Department of Microbiology and Molecular Medicine, \\ University of Geneva, \\ Geneva, Switzerland \\ D. Trono \\ Frontiers in Genetics National Center for Competence in Research, \\ Lausanne, Switzerland \\ D. Trono \\ Federal Institute of Technology, \\ Lausanne, Switzerland
}

the newly engineered cells were assessed in vitro by RTPCR, in situ hybridisation, immunostaining and radioimmunoassay. $P D X 1$-transduced hepatocytes were further studied in vivo by injecting them under the renal capsule of diabetic SCID mice.

Results Isolated rat hepatocytes were efficiently transduced with the lentiviral vector, as assessed by green fluorescent reporter gene expression. The transduced cells exhibited insulin at both mRNA (RT-PCR, in situ hybridisation) and protein levels (immunostaining and radioimmunoassay). Moreover, insulin secretion by the engineered cells was dependent on glucose and sulfonylurea. Other beta cell genes, including those encoding solute carrier family 2 (facilitated glucose transporter), member 2 (Slc2a2), glucokinase $(G c k)$, ATP-binding cassette, sub-family C (CFTR/ MRP), member 8 (Abcc8), the potassium inwardly-rectifying channel, subfamily J, member 11 (Kcnj11) and proprotein convertase subtilisin/kexin type 1 (Pcsk1) were also expressed. The PDX1-transduced hepatocytes expressed several pancreatic transcription factors related to early pancreatic endocrine development (endogenous $P d x 1$, neurogenic differentiation factor 1 [Neurod1], and NK6 transcription factor related, locus $1[N k x 6-1])$ as well as the late-stage pancreatic transcription factors (paired box gene 4 [Pax4], paired box gene 6 [Pax 6$]$, and v-maf musculoaponeurotic fibrosarcoma oncogene homolog A [Mafa]). Transplantation of $3 \times 10^{6}$ transdifferentiated liver cells under the renal capsule of seven streptozotocin-induced diabetic SCID mice resulted in significant reduction of nonfasting blood glucose levels from $30.7 \pm 1.3$ to $8.7 \pm$ $3.7 \mathrm{mmol} / \mathrm{l}$ (mean $\pm \mathrm{SEM}, p=0.01$ ), in 6 to 8 weeks. Removal of the graft resulted in severe hyperglycaemia.

Conclusions/interpretation Ex vivo lentiviral-mediated $P D X 1$ expression in isolated adult liver cells represents a potential model for type 1 diabetes mellitus therapy. 
Keywords Gene therapy · Hepatocytes · Lentivirus . $P D X 1 \cdot$ Transplantation $\cdot$ Type 1 diabetes

\begin{tabular}{|c|c|}
\hline \multicolumn{2}{|c|}{ Abbreviations } \\
\hline $\mathrm{ABCC} 8$ & ATP-binding cassette, sub-family C (CFTR/ \\
\hline & $\begin{array}{l}\text { MRP), member } 8 \text { (previously known as } \\
\text { sulfonylurea receptor } 1 \text { [SUR1]) }\end{array}$ \\
\hline cDNA & complementary DNA \\
\hline DIG & digoxigenin \\
\hline EGFP & enhanced green fluorescent protein \\
\hline GCK & glucokinase \\
\hline HIV & human immunodeficiency virus \\
\hline IPF1 & $\begin{array}{l}\text { insulin promoter factor } 1 \text {, homeodomain } \\
\text { transcription factor }\end{array}$ \\
\hline $\mathrm{KCNJ8}$ & $\begin{array}{l}\text { potassium inwardly rectifying channel, sub- } \\
\text { family J, member } 8 \text { (previously known as } \\
\text { Kir6.1) }\end{array}$ \\
\hline KCNJ11 & $\begin{array}{l}\text { potassium inwardly rectifying channel, sub- } \\
\text { family J, member } 11 \text { (previously known as } \\
\text { Kir6.2) }\end{array}$ \\
\hline MAFA & $\begin{array}{l}\text { v-maf musculoaponeurotic fibrosarcoma on- } \\
\text { cogene homolog A (avian) }\end{array}$ \\
\hline MOI & multiplicity of infection \\
\hline NEUROD1 & neurogenic differentiation 1 \\
\hline NKX6-1 & NK6 transcription factor related, locus 1 \\
\hline PAX4 & paired box gene 4 \\
\hline PAX6 & paired box gene 6 \\
\hline PCSK1 & $\begin{array}{l}\text { proprotein convertase subtilisin/kexin type } 1 \\
\text { (previously known as prohormone conver- } \\
\text { tase } 1,[\mathrm{PC} 1 / 3] \text { ) }\end{array}$ \\
\hline PDX1 & pancreatic duodenal homeobox 1 \\
\hline PPY & pancreatic polypeptide \\
\hline SLC2A2 & $\begin{array}{l}\text { solute carrier family } 2 \text { (facilitated glucose } \\
\text { transporter), member } 2 \text { (previously known as } \\
\text { glucose transporter } 2 \text { [GLUT2]) }\end{array}$ \\
\hline TU & transducing units \\
\hline
\end{tabular}

15]. Later in life, it is required for maintaining beta cell identity by positively regulating the expression of insulin and islet amyloid polypeptide [16-18] and negatively regulating glucagon secretion [19]. PDX1 regulates the expression of solute carrier family 2 (facilitated glucose transporter), member 2 (SLC2A2, previously known as glucose transporter 2 [GLUT2]) $[16,20]$ and glucokinase $(G C K)$ [21], the two key components of the beta cell glucose-sensing system. PDX1 is also one of the main transcription factors mediating the stimulatory effect of glucose on insulin gene expression and secretion [22, 23]. Recently, Ferber and colleagues showed that adenoviralmediated $P D X 1$ expression in liver activates insulin and other beta cell specific genes [24, 25].

The lentiviral vectors derived from human immunodeficiency virus (HIV)-1 have the unique ability to transduce both non-dividing cells and hepatocytes [26-28]. They integrate stably into the genome of the host cell and are therefore potential vectors for long-term expression of therapeutic genes. Moreover, they overcome most of the drawbacks of adenoviral vectors, such as toxicity and immunogenicity [29]. Another limitation of adenoviral delivery of $P D X 1$ is that it results in only about one copy per liver cell. Fetal human progenitor liver cells became insulin-producing cells in response to expression of $P D X 1$ via a lentivirus (equine infectious anaemia virus-based vector) [30]. However, this method has not been tested using mature adult hepatocytes or a human lentiviral vector. In the present study, we examined the hypothesis that we could achieve glucose-sensitive insulin secretion at a level sufficient to regulate glucose homeostasis in a diabetic animal model using an ex vivo cell therapy approach. We expressed high levels of $P D X 1$ in isolated adult liver cells in vitro using a human lentiviral vector, transplanted the cells into diabetic mice, and examined the effects on insulin expression and secretion.

\section{Materials and methods}

Isolation and culture of adult rat hepatocytes Animals were kept under standard laboratory conditions and had free access to food and water. The study was approved by the animal welfare committee of the Technion, and 'Principles of laboratory animal care' (NIH publication no. 85-23, revised 1985; http:/grants1.nih.gov/grants/olaw/references/ phspol.htm) were followed.

Primary rat hepatocytes were isolated from male Lewis rats (150-180 g; Harlan Laboratories, Jerusalem, Israel) by a two-step collagenase method, as previously described [31, 32]. Briefly, following anaesthesia by intramuscular injection of a ketamine/xylazine mixture $(100$ and $10 \mathrm{mg} / \mathrm{kg}$, respectively), the liver was perfused in situ through the 
portal vein with $0.05 \%$ collagenase type IV (Sigma Chemical, St Louis, MO, USA). Parenchymal hepatocytes were purified by low-speed, iso-density Percoll centrifugation (Sigma) [33]. Non-parenchymal cells were identified by their size and morphology and made up less than $1 \%$ of the cells. Isolated hepatocytes were plated on a single layer of collagen gel [32] for in vitro experiments or in 100-mm plates (Primaria; Becton Dickinson, Franklin Lakes, NJ, USA) for in vivo experiments. The primary hepatocytes were seeded in William's E medium (Biological Industries, Beth Haemek, Israel) supplemented with 5\% FCS, $10 \mathrm{mg} / \mathrm{l}$ insulin-transferrin-selenium supplement (Roche Applied Science, Mannheim, Germany), $10 \mathrm{mmol} / 1$ nicotinamide, $10 \mathrm{ng} / \mathrm{ml}$ endothelial growth factor, $2 \mathrm{mmol} / 1$ L-glutamine, $2 \mathrm{mmol} / 1$ sodium pyruvate, $20 \mathrm{mmol} / 1 \mathrm{HEPES}$, and antibiotics. The medium was replaced $4 \mathrm{~h}$ later and daily thereafter with serum-free supplemented William's medium.

Vector production and in vitro transduction Vesicular stomatitis virus G-pseudotyped, HIV-1-based lentiviral vector particles carrying complementary DNA (cDNA) for the human $P D X 1$, were produced by cotransfection of four plasmids ( $p C M V D R-8.92,7.5 \mu \mathrm{g} ; p R S V-R e v, 5 \mu \mathrm{g} ; p M D . G$, $3 \mu \mathrm{g}$; WPIG-PDXI vector, $10 \mu \mathrm{g}$ ) in $293 \mathrm{~T}$ cells via the calcium phosphate precipitation method [34]. The plasmid constructs were prepared by two of us (D. Trono and P. Salmon). Briefly, the human PDX1 gene and the gene encoding enhanced green fluorescent protein (EGFP) were subcloned into a self-inactivating vector, under the transcriptional control of the human elongation factor- $1 \alpha$ promoter [35]. An empty vector was constructed by excising the $P D X 1$ insert from the original vector using specific primers and a kit (QuikChange; Stratagene, La Jolla, CA, USA). The packaging plasmid, $p C M V D R-8.92$, is a capsid-encoding plasmid derived from $p C M V D R-8.91$, which contains the tat coding sequence and a deletion of the BamHI restriction site in the coding region of rev. The rev-expressing plasmid ( $p R S V-R e v)$ and the plasmid encoding the $V S V-G$ envelope $(p M D . G)$ are described elsewhere $[34,36]$.

High viral titres of $5-10 \times 10^{5}$ transducing unit per $\mathrm{ml}$ were regularly obtained by transient transfection of the four plasmids. The titration of the viral vector was performed in Cos7 cells by fluorescence-activated cell sorter.

At 8 to $10 \mathrm{~h}$ after seeding, hepatocytes were transduced by exposing them to ten to 15 multiplicity of infection (MOI) of the PDXI-lentiviral vector for $12 \mathrm{~h}$ in the presence of $4 \mu \mathrm{g} / \mathrm{ml}$ polybrene (Sigma).

Detection of insulin expression by RT-PCR Total RNA was extracted with Trizol reagent. Reverse transcription was performed on $2 \mu \mathrm{g}$ total RNA using a kit (Reverse-iT 1st Strand Synthesis; ABgene, Epsom, UK) according to the manufacturer's protocol. cDNA was amplified by using the primer pairs and conditions listed (see Electronic supplementary material [ESM] Table 1). PCR products were separated by electrophoresis in $2 \%$ agarose gels and visualised by ethidium bromide staining.

Detection of insulin expression by in situ hybridisation We used probes for mouse insulin-1 (677 bp) cloned in pBluescribe (Vector Cloning System, San Diego, CA, USA). Antisense and sense probes for in situ hybridisation were produced by transcription using an RNA labelling kit (Sp6/T7 digoxigenin [DIG]-RNA; Boehringer, Mannheim, Germany) following the company's instructions. The transduced and untransduced hepatocytes were hybridised with sense and anti-sense DIG-labelled RNA probes as described [37]. Hybrids were detected using anti-DIG antibodies conjugated with rhodamine (Cat. no 1207750; Roche).

Insulin immunostaining Transduced and untransduced hepatocytes were fixed in $4 \%$ paraformaldehyde for 10 min and then blocked with $10 \%$ goat serum, $1 \%$ BSA, $0.5 \%$ Triton X-100 in PBS for 30 min. The cells were incubated with mouse monoclonal anti-insulin antibodies (cat. no. I2018; Sigma) (1:500) for $2 \mathrm{~h}$ at room temperature. The primary antibodies were detected with a cyanine Cy3conjugated goat anti-mouse antibody (Cat. no. 115-165062; Jackson ImmunoResearch Laboratories, West Grove, PA, USA) (1:500) for $1 \mathrm{~h}$ at room temperature.

At 8 weeks after subcapsular kidney transplantation (see below), the kidney with the implant was dissected, and embedded in paraffin according to standard procedures. Sections $(5 \mu \mathrm{m})$ were deparaffinised, rehydrated, microwaved in $10 \mathrm{mmol} / \mathrm{l}$ sodium citrate $(\mathrm{pH} 6.0)$ for $20 \mathrm{~min}$ and then blocked as described above. Endogenous peroxidase activity was blocked with $3 \% \mathrm{H}_{2} \mathrm{O}_{2}$ in methanol for $10 \mathrm{~min}$. Immunohistochemical detection of insulin was performed with guinea pig anti-insulin antibodies (1:50) (DakoCytomation, Glostrup, Denmark) overnight at $4^{\circ} \mathrm{C}$, followed by the avidin-biotin-peroxidase complex detection method (BioGenex Laboratories, San Ramon, CA, USA). Diaminobenzidine substrate solution was used to produce a redbrown precipitate. Analysis and photo-documentation were performed using an Olympus microscope (IX81; Olympus America, Melville, NY, USA) and a charge-coupled camera (DP70; Olympus).

In vitro insulin production from transduced hepatocytes Primary hepatocytes were plated in 12-well plates at 200,000 cells per well, on collagen gel $(100 \mu \mathrm{l} /$ well $)$, cultured and infected as described before. On the eighth day of culture, the medium was removed and the cells were washed twice with KRB supplemented with $1 \%$ BSA (Sigma). The cells 
were preincubated in $\mathrm{KRB}$ at $37^{\circ} \mathrm{C}$ for $1 \mathrm{~h}$, followed by incubation in $0.5 \mathrm{ml} /$ well fresh $\mathrm{KRB}$ containing the indicated glucose concentration for the indicated periods. In some experiments, secretagogues were added to the glucose (200 nmol glibenclamide or $40 \mathrm{nmol}$ repaglinide) or the glucose was replaced with its non-metabolisable analogue, L-glucose.

At the end of the incubation period, the insulin released into the incubation buffer was measured by radioimmunoassay according to the manufacturer's instructions (cat. no. SRI-13K; Linco, St Charles, MO, USA). To determine cellular insulin content, the cells were scraped from the wells with $3 \mathrm{~mol} / \mathrm{l}$ acetic acid, lysed by three freeze-thaw cycles, and lyophilised. The samples were reconstituted in $1 \%$ SDS prior to the insulin assay. The cell protein concentration for each well was also determined using a kit (Protein Assay Kit; Bio-Rad, Hercules, CA, USA), and insulin values were normalised to the protein concentration.

Metabolic labelling studies PDX1-transduced hepatocytes were cultured for 10 days, as described before. After $1 \mathrm{~h}$, incubation in leucine free-RPMI 1640 medium (cat. no. SLM-200; Chemicon, Temecula, CA, USA), the cells were then metabolically labelled for different periods of time (4 and $16 \mathrm{~h}$ ) with $3.7 \mathrm{MBq}$ per well $\left[{ }^{3} \mathrm{H}\right]$ leucine (cat. no. TRK510-5MCI; Amersham, Bucks, UK). Labelled cells were dissociated in $0.2 \%$ trifluoroacetic acid and sonicated for $30 \mathrm{~s}$. Insulin and proinsulin-related proteins were analysed by HPLC (courtesy of G. Leibowitz, Hadassa Medical Center, Jerusalem, Israel).

Cell transplantation Transduced hepatocytes were collected with $1 \mathrm{ml}$ of $0.05 \%$ trypsin (Sigma) per $100-\mathrm{mm}$ Primaria dish. The cells were resuspended in $50 \mu \mathrm{l}$ normal saline just before the infusion.

We rendered 6-week-old SCID-beige male mice (Harlan, Jerusalem, Israel) hyperglycaemic by i.p. injection of $200 \mathrm{mg} / \mathrm{kg}$ body weight streptozotocin. Only mice with blood glucose levels above $16 \mathrm{mmol} / \mathrm{l}$, for at least 4 days, were used as cell recipients. The suitable animals were maintained on daily injections of $1 \mathrm{U}$ long-acting insulin (Lantus; Sanofi-Aventis, Paris, France) for 2 days before and 4 days following transplantation. Mice were anaesthetised by intramuscular injection of ketamine/xylazine $(150$, $10 \mathrm{mg} / \mathrm{kg}$, respectively) and transplanted with $3 \times 10^{6}$ viable hepatocytes under the left renal capsule using a 30-gauge needle. Blood glucose levels were monitored in samples obtained from the tail veins of fed mice using a glucometer (FreeStyle; Thera Sense, Alameda, CA, USA). At the indicated time point, the mice were anaesthetised and subjected to left kidney nephrectomy, and blood glucose levels were monitored for an additional 2 days.
Intraperitoneal glucose tolerance test Animals were fasted for $6 \mathrm{~h}$ and injected i.p. with $50 \%$ dextrose solution at a dose of $1 \mathrm{~g} / \mathrm{kg}$ body weight. Blood glucose was measured before and at 30-min intervals after glucose infusion.

Statistical analysis The differences in various experimental conditions and time points were analysed with Student's $t$ tests. Differences were considered significant at $p<0.05$.

\section{Results}

Mature hepatocytes were transduced overnight in primary culture with ten to $15 \mathrm{MOI}$ of $P D X 1$-lentiviral vector, and then examined 8 days later by RT-PCR, in situ hybridisation, immunocytochemistry and RIA.

Expression of beta cell-specific and glucose-sensing genes in PDX1-transduced hepatocytes As expected, lentiviraltransduced hepatocytes expressed the exogenously introduced human PDX1 (Fig. 1a). Expression of endogenous rat $P d x 1$, which was probably activated by the human PDX1 transgene, was also detected (Fig. 1b). The rat insulin genes, Insulin I and II, and the gene encoding proprotein convertase subtilisin/kexin type 1 (Pcskl; previously known as prohormone convertase $1,[P C 1 / 3])$ were expressed in transduced hepatocytes and in RNA derived from rat pancreas, but not in untransduced hepatocytes (Fig. 1b), suggesting that PDX1-transduced hepatocytes could potentially produce mature insulin. Many constituents of the glucose-sensing beta cell cascade are identical or similar in both liver and beta cells, including Slc2a2, Gck [38], ATP-binding cassette, sub-family C (CFTR/MRP), member 8 (Abcc 8 ; previously known as sulfonylurea receptor 1 [Surl]) and the potassium inwardly rectifying channel, subfamily J (Kcnj11; previously known as Kir6.2) [39]. Indeed, Slc2a2, the liver-type $G c k$, and $A b c c 8$ were natively expressed in primary hepatocytes and were not affected by human $P D X 1$ overexpression (Fig. 1b). In vivo production of PDX1 in liver also induces expression of the pancreas-type Gck [40]. The liver expresses the potassium inwardly rectifying channel, subfamily J, member 8 (Kcnj8; previously known as Kir6.1), a different subunit from the Kcnj11 found in pancreas [39]. In our hands, two forms of the potassium channel were expressed in transduced hepatocytes, while the control untransduced hepatocytes expressed only one (most probably Kcnj8). The second form in the transduced hepatocytes is similar to the one expressed in the pancreas, being most probably Kcnj11 (Fig. 1b). The PDX1-transduced hepatocytes also expressed several pancreatic transcription factors related to early pancreatic endocrine development (endogenous $P d x l$, neurogenic differentiation 
a

\section{Control Transduced hepatocytes hepatocytes}

Human IPF1 (PDX1)

b

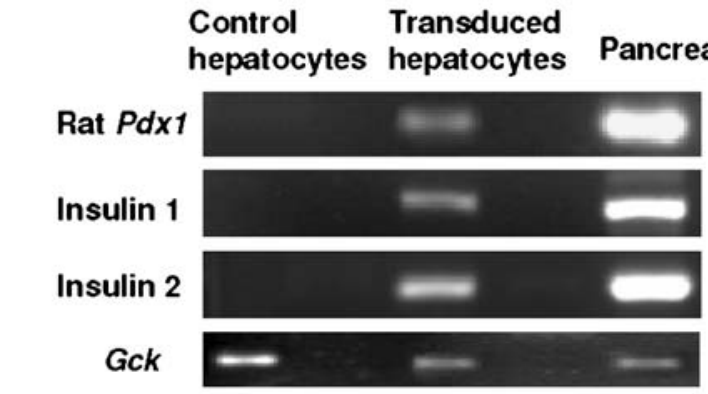

Pcsk (Pc1)

\section{Sic2a2 (Glut2) \\ Abcc8 (SUR1) \\ Kcnj8 and 11 \\ (KIR6.1 and 6.2)}
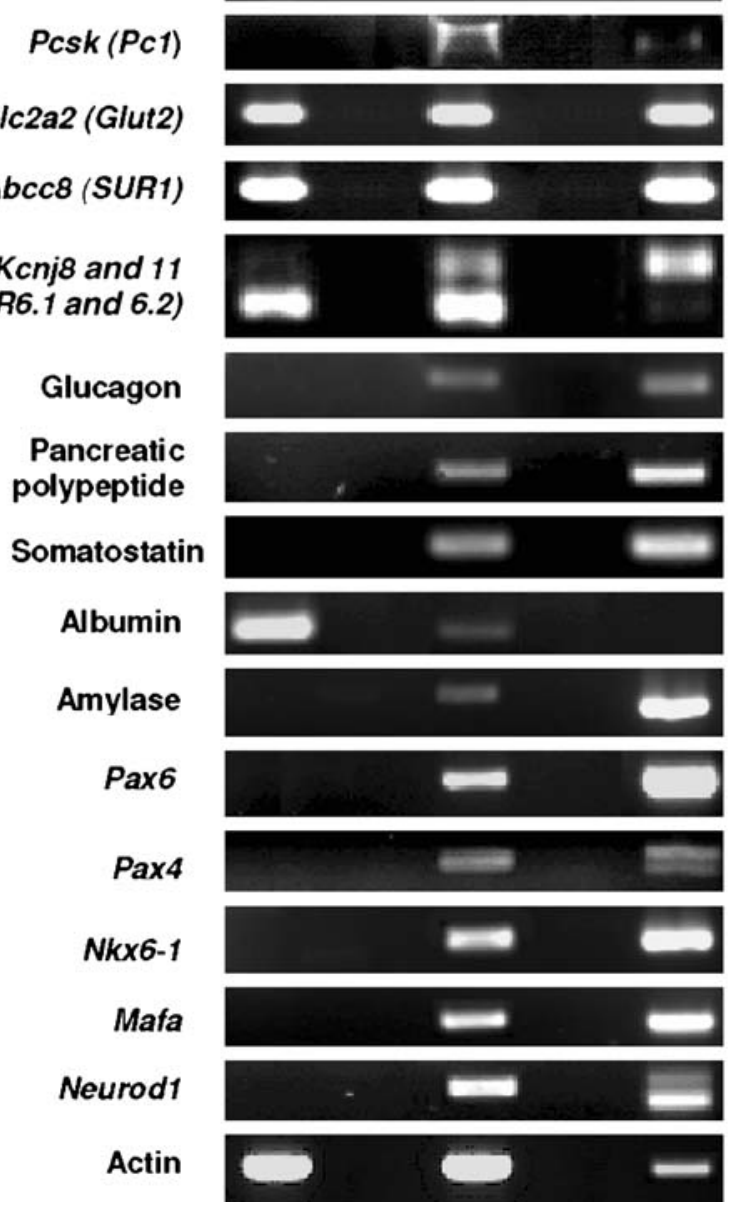

Fig. 1 RT-PCR analysis of gene expression in PDX1 (IPF1)transduced hepatocytes. mRNA extracted from transduced and untransduced hepatocytes was subjected to RT-PCR analysis with primers for the indicated genes. a Analysis of expression of human IPF1 (PDX1), with plasmid DNA as positive control. b Analysis of expression of rat pancreatic genes, with rat pancreas extract as positive control. Primers for actin were used as internal control. The absence of DNA contamination in RNA samples was confirmed where possible with PCR primers flanking an intron or by omitting the reverse transcription step. The amount of the input cDNA was the same for control pancreas and for PDX1-transduced and untransduced hepatocytes
1 [Neurod1], and NK6 transcription factor related, locus 1 [Nkx6-1]) as well as the late-stage pancreatic transcription factors (paired box genes 4 and 6 [Pax4, PaxO and v-maf musculoaponeurotic fibrosarcoma oncogene homolog A (avian) $[$ Mafa] $)$ (Fig. 1b).

Beside beta cell-specific genes, $P D X 1$-overexpression in primary hepatocytes induced expression of other pancreatic endocrine and exocrine genes such as glucagon, somatostatin, pancreatic polypeptide and amylase, while expression of albumin was downregulated in PDX1-transduced cells (Fig. 1b).

The expression of human PDXI gene in transduced hepatocytes is also evident from the expression of the reporter gene encoding EGFP, both genes being subcloned into the same vector (Fig. 2a). Direct immunofluorescent examination of the cultured cells shows that, at ten to 15 MOI lentiviral vector, virtually all hepatocytes were infected (Fig. 2b).

Insulin mRNA expression in PDX1-transduced cells was further revealed by in situ hybridisation. Insulin mRNA staining was present exclusively in transduced hepatocytes hybridised with an antisense RNA probe (Fig. 2d), but neither in control untransduced hepatocytes (Fig. 2e), nor in transduced hepatocytes following sense RNA probe treatment (Fig. 2f).

Insulin protein is present in PDX1-transduced hepatocytes In order to determine whether the insulin protein was efficiently translated in these newly engineered cells, an immunofluorescence assay was performed. As shown in Fig. $2 \mathrm{~g}$, the transduced hepatocytes clearly exhibited cytoplasmic insulin immunoreactivity and a cell distribution in islet-like groups. Untransduced hepatocytes lacked insulin immunoreactivity (Fig. 2h). The PDX1-transduced cells appeared to be a homogeneous population, with most cells staining positive for both insulin mRNA and protein, confirming that the insulin protein immunostaining was due to insulin synthesis and not just to uptake from the medium, as has been shown in embryonic stem cells [41].

Glucose-stimulated insulin production and secretion from transduced hepatocytes We next studied changes in insulin cell content and insulin release in response to glucose or various secretagogues (Fig. 3).

Insulin content and insulin release showed similar dose-response curves, with submaximal stimulation at $5 \mathrm{mmol} / \mathrm{l}$ glucose (Fig. 3a). Maximal stimulation was achieved at $25 \mathrm{mmol} / \mathrm{l}$ glucose, with a 2.7 -fold increase in cell content of insulin and a 2.3-fold increase of insulin in the medium ( $p=0.001$ and $p=0.02$, respectively). The metabolically inactive analogue of glucose, L-glucose, did not stimulate insulin synthesis or release from the transduced cells (Fig. 3a). Adding secretagogues to $5 \mathrm{mmol} / \mathrm{l}$ glucose 

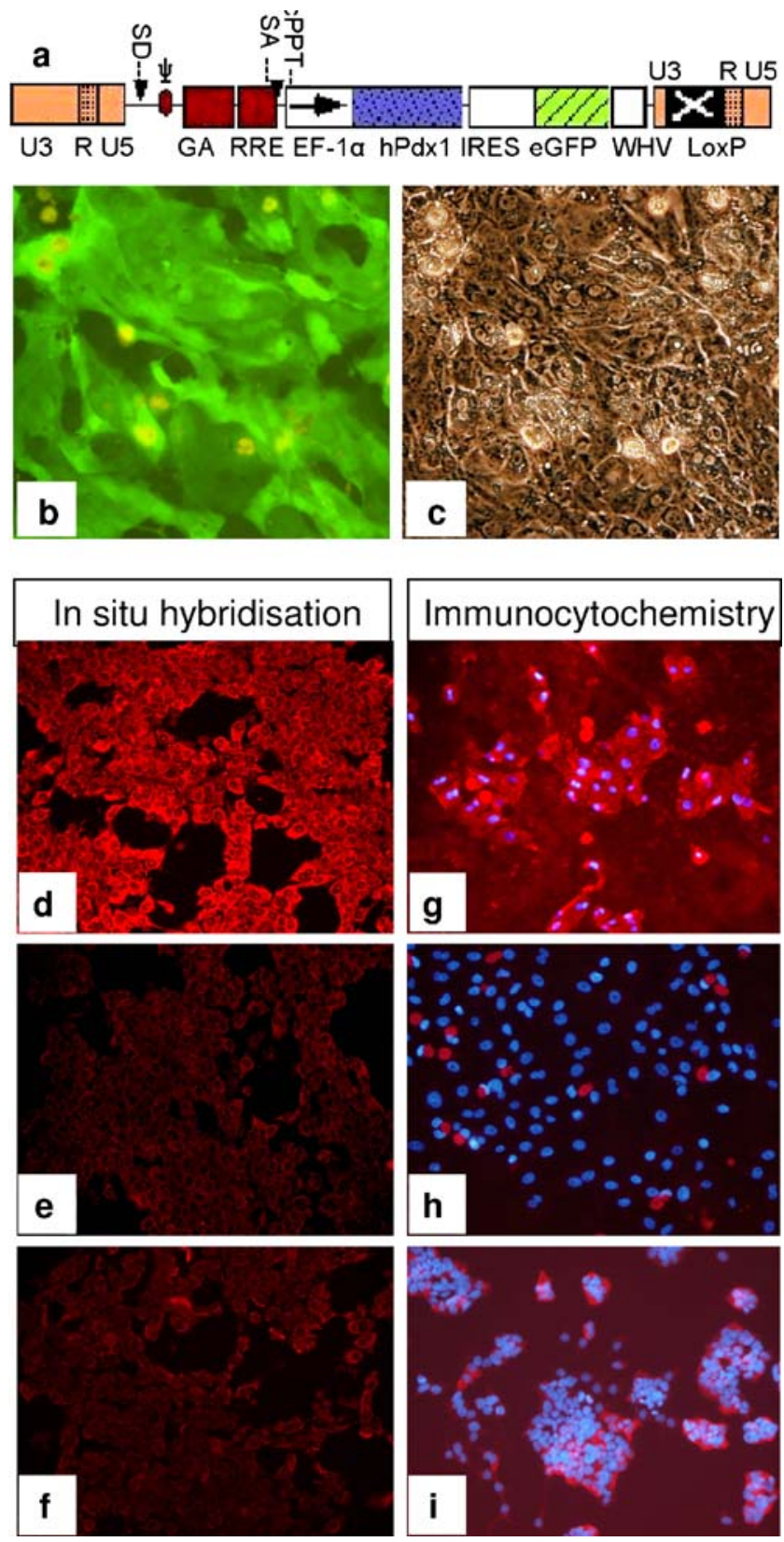

resulted in additional insulin release (Fig. 3b). In normal glucose medium, repaglinide enhanced insulin release 3.4fold $(p<0.0001)$ and glibenclamide 2.7-fold $(p=0.003)$ over the basal level (Fig. 3b).

Insulin release from $P D X 1$-transduced hepatocytes in response to $25 \mathrm{mmol} / 1$ glucose stimulation was $48 \pm 16 \mathrm{ng}$ $\mathrm{mg}$ protein of cell lysate ${ }^{-1} 2 \mathrm{~h}^{-1}$ (mean \pm SEM; range 18 $72 \mathrm{ng} \mathrm{mg}^{-1} 2 \mathrm{~h}^{-1}$ ). Small amounts of insulin, most probably carried over from the culture medium, were detected in untransduced hepatocytes, and were subtracted from the above value.

In another series of experiments, insulin progressively accumulated in the incubation medium over an 8-h time
4 Fig. 2 a-c PDX1-EGFP expression in primary rat hepatocytes. a The lentiviral vector used to express PDX1-EGFP. Orange boxes: viral LTR with (black $X^{\prime}$ d-out box) or without a U3 deletion; $S D$ Major splice donor site, $\Psi$ encapsidation signal, including the $5^{\prime}$ portion of gag (GA), RRErev response element, $S A$ splice acceptor site, $c P P T$ central polypurine tract, $W H V$ posttranscriptional regulatory element of woodchuck hepatitis virus, $E F-1 \alpha$ human elongation factor $1 \alpha$, IRES internal ribosome entry site, LoxPLoxP gene, target of bacterial Cre recombinase (acc. no. AF237862). Representative fluorescence (b) and phase-contrast (c) pictures of the same field of rat hepatocytes 8 days after transduction with PDX1-lentiviral vectors. Original magnification $\times 300$. $\mathbf{d}-\mathbf{i}$ Insulin expression in PDX1-transduced hepatocytes. Transduced hepatocytes at 8 days $(\mathbf{d}, \mathbf{f})$ and untransduced hepatocytes (e) were examined for insulin mRNA; transduced (g) and untransduced (h) were also examined for insulin protein presence. In situ hybridisation technique, using DIG-labelled antisense $(\mathbf{d}, \mathbf{e})$ or sense (f) probe for insulin was used to assess the presence of insulin mRNA. The positive cells are stained in red and are present exclusively in antisense probe treatment of transduced hepatocytes (d). Immunocytochemistry using specific mouse anti-insulin antibody was used to detect the presence and localisation of insulin protein $(\mathbf{g}-\mathbf{i})$. The positive cells are stained in red. Beta-TC cell line secreting insulin was positive control (i). Nuclear staining was done with DAPI

course when three glucose concentrations $(5,10$ and $25 \mathrm{mmol} / \mathrm{l}$ ) were tested (Fig. 4).

Transplantation of transduced hepatocytes under the kidney capsule of diabetic immunocompromised mice reverses diabetes In order to examine the in vivo function of the transduced cells, human $P D X 1$-transduced cells were implanted into streptozotocin-induced diabetic SCID-beige mice. Blood glucose decreased significantly in diabetic mice implanted with $P D X 1$-transduced hepatocytes $(n=7)$, from $30.7 \pm 1.3 \mathrm{mmol} / 1$ before cell transplantation to $8.7 \pm$ $3.7 \mathrm{mmol} / 12$ months after transplantation (mean \pm SEM, $p=0.01)$ (Fig. 5a). In contrast, control mice $(n=2)$ implanted with hepatocytes transduced with lentiviral vectors lacking the insert retained their high pretransplantation or even had slightly higher glucose levels. Furthermore, the treated diabetic mice gained $38 \%$ of their starting body weight $(p=0.0076)$, while the control mice gained only $12.7 \%$ of their body weight $(p=0.047)$. An intraperitoneal glucose tolerance test showed a significant clearance rate $1 \mathrm{~h}$ after glucose infusion in animals implanted with $P D X 1$-transduced hepatocytes $(p=0.03)$ (Fig. 5b). Removal of the graft-bearing kidney from two $P D X 1$-treated mice resulted in the resumption of severe diabetes, further supporting the idea that the graft had accounted for the reversal of hyperglycaemia (Fig. 5a).

At 8 weeks after transplantation we removed the implanted kidneys in the remaining animals. Examination of the histology of the grafts by haematoxylin-eosin staining showed circumscribed tissue without evidence of invasion into the adjacent kidney parenchyma. Small blood vessels could be seen within the grafts. Immunohistochemistry with an anti-insulin antibody showed that insulin was present in most of the graft cells (see ESM Fig. 1). 


\section{Discussion}

The present study demonstrates that primary hepatocytes can be engineered to function in vitro and in vivo as beta cells. The transdifferentiated cells exhibit the following distinct regulatory beta cell-like functions: (1) they secrete insulin in response to glucose and secretagogues in a dosedependent manner (Figs. 3 and 4); (2) they are morphologically rearranged like beta cell islets both in vitro (Fig. 2g), and in rat liver in vivo (data not shown); (3) they are able to normalise in vivo plasma glucose levels of diabetic mice when implanted under the animal kidney capsule (Fig. 5); and (4) they reverse the weight loss associated with the disease in diabetic mice. These functions are essential to the control of glycaemia in humans as well as other mammals.

The ability of PDX1 to induce transdifferentiation of liver cells into insulin-secreting cells, studied mostly in vivo, has been quite controversial. Ferber et al. [24, 25] documented that production of PDX1 in 30 to $50 \%$ of mouse liver cells by adenoviral-mediated gene transfer enabled a small proportion of the cells to produce insulin in

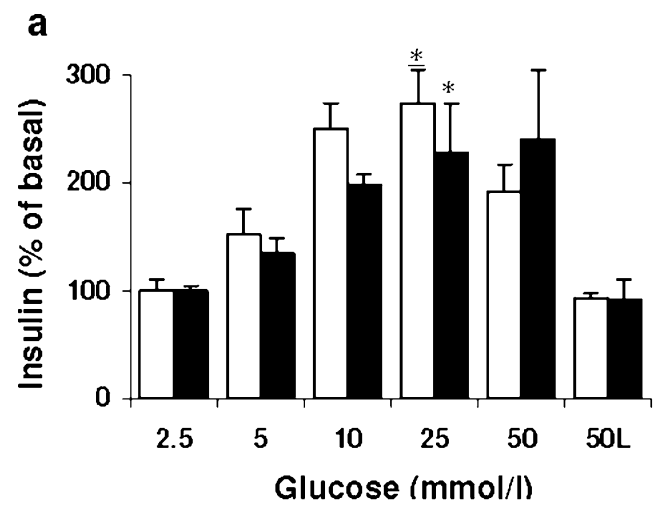

b

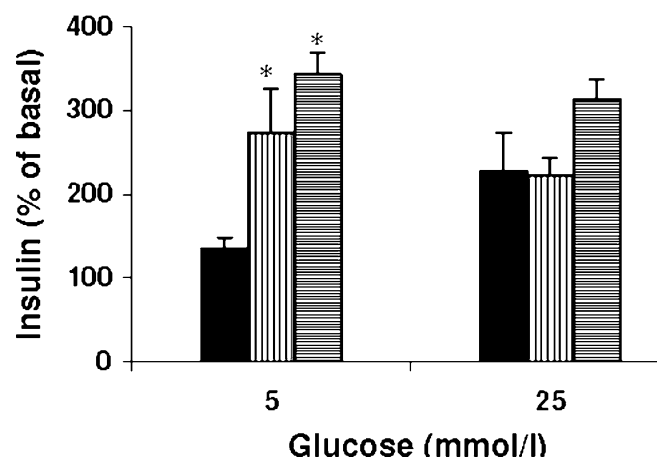

Fig. 3 Insulin synthesis and secretion induced by glucose \pm secretagogues in $P D X 1$-transduced hepatocytes. Data represent the mean \pm SEM for six to nine wells per condition from three different experiments expressed as percent increase in insulin release or content relative to cells incubated in $2.5 \mathrm{mmol} / 1$ glucose. a White bars: insulin content; black bars: insulin released into incubation medium. b Black bars: insulin released into incubation medium; vertical lined bars: glibenclamide; horizontal lined bars: repaglinide; $\mathrm{L}=\mathrm{L}$-glucose; Asterisk: $p<0.05$ compared with secretion at $2.5 \mathrm{mmol} / 1$ glucose

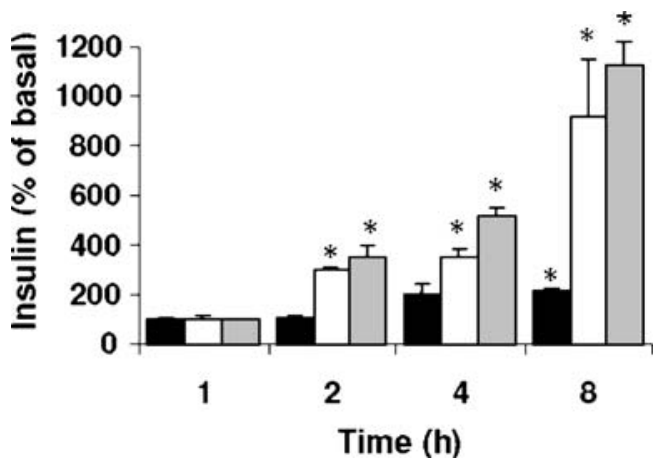

Fig. 4 Time course of glucose-induced insulin secretion from $P D X 1$ transduced hepatocytes. Data represent the mean \pm SEM for six to nine independent wells per condition from three different experiments expressed as percent increase in insulin release relative to cells incubated in each glucose concentration for $1 \mathrm{~h}$. Black bars: insulin released in $5 \mathrm{mmol} / \mathrm{l}$ glucose; white bars: insulin released in $10 \mathrm{mmol} / 1$ glucose; grey bars: insulin released in $25 \mathrm{mmol} / 1$ glucose incubation medium. Asterisk: $p<0.05$ compared with secretion at $1 \mathrm{~h}$ for each glucose concentration

vivo and to prevent streptozotocin-induced diabetes. However, a similar study using a newer generation of adenoviral vector for $P D X 1$ delivery showed only a transient and partial lowering of the blood glucose levels [42]. In another model [40], induction of PDX1 in more than $50 \%$ of hepatocytes in a conditional transgenic mouse initiated, but did not complete the differentiation of liver cells into mature pancreatic cells. In another study, expression of an activated form of $P D X 1$ carrying the VP16 transcriptional activation domain in transgenic tadpoles led to conversion of most of the liver to pancreas containing both exocrine and endocrine cells [43]. However, in the same study, no evidence of transdifferentiation was seen when an unmodified form of $P D X 1$ was used, suggesting that $P D X 1$ requires the recruitment of other protein partners, transcription factors, or cofactors in order to fully exert its function or to overcome repressors in the liver.

In vivo expression of $P D X 1$ by adenoviral gene delivery or by transgenic expression delivers only about one $P D X 1$ gene copy per liver cell. In the present study, we aimed to augment the copy number in the transduced cells. We showed that high expression of $P D X 1$ can be induced ex vivo in isolated rat liver cells using a lentiviral-based vector. These findings are consistent with other recent studies using lentiviral vectors [27, 28]. In our study, the infection of rat hepatocytes at 10 to 15 MOI resulted in gene transfer to essentially $100 \%$ of the liver cells, probably with multiple proviral integrations per transduced cell. Furthermore, cross-species transplantation into diabetic SCID mice resulted in significant amelioration of hyperglycaemia. This correction was possible without preselection of transduced cells before transplantation. A further increase in the MOI of the lentiviral infection was associated with an increase in insulin secretion but also 

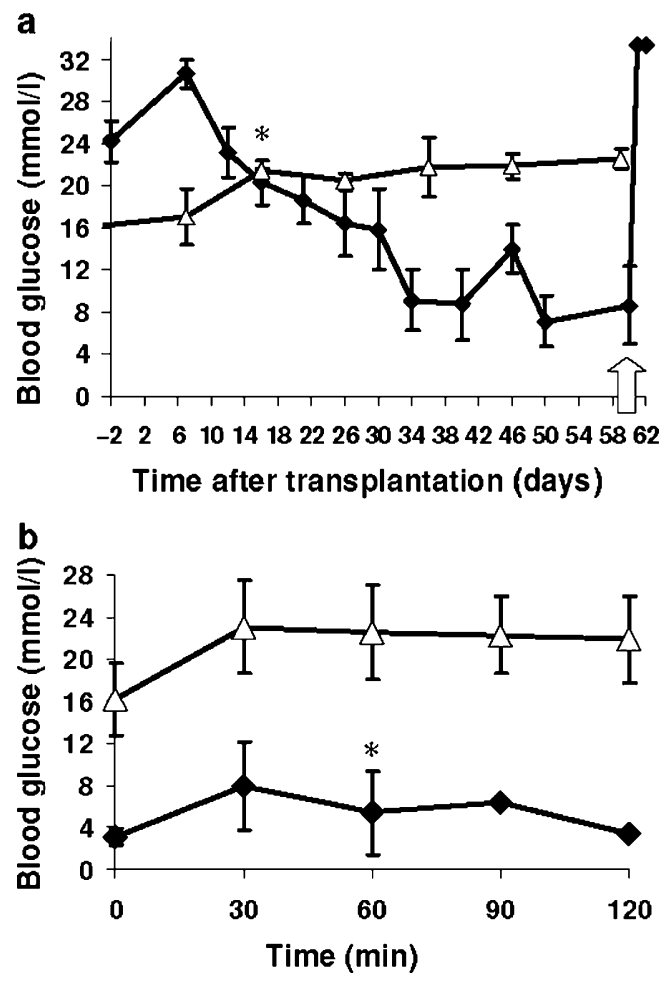

Fig. 5 Rat hepatocytes transduced ex vivo affect in vivo blood glucose levels. a Fed blood glucose levels. SCID mice were rendered diabetic (200 mg streptozotocin/ $\mathrm{kg}$ body weight, 1 week before) and then injected under renal capsule with $3 \times 10^{6} \mathrm{PDX} 1$-transduced hepatocytes (black symbols, $n=7$ ). Control diabetic mice were injected with equivalent amount of transduced hepatocytes with lentiviral vector but without $P D X 1$ insert (white triangles, $n=2$ ). Non-fasting blood glucose levels were measured at indicated time points, at 09:00 hours. On day 60 after transplantation (arrow), two mice underwent removal of kidney bearing the graft and blood glucose levels were followed for 2 more days. Asterisk: $p=0.0018$ for reduction in blood glucose level at 16 days, compared with blood glucose at 7 days after transplantation. b Glucose tolerance test performed on mice at 60 days after transplantation. After $6 \mathrm{~h}$ of food deprivation, glucose ( $1 \mathrm{~g} / \mathrm{kg}$ body weight) was administered i.p. in mice treated with $P D X 1$-transduced cells or in control mice transplanted with transduced hepatocytes with lentiviral vector lacking $P D X 1$. Results are means of two animals in each group. Black symbols: with PDX1; open symbols: control. Asterisk: $\mathrm{p}<0.05$ for reduction in blood glucose level at $60 \mathrm{~min}$, compared with blood glucose at $30 \mathrm{~min}$ after glucose infusion

with a tendency of the cells to lose their sensitivity to glucose (data not shown).

Recently, Ferber et al. [24] published similar data using adenoviral-mediated $P D X 1$ expression in human adult hepatocytes. However, the adenoviral vector enabled transduction of only $50 \%$ of cultured hepatocytes, even at very high doses of viral vector $(\mathrm{MOI}=500)$. Moreover, less than half of the PDX1-transduced hepatocytes produced insulin, suggesting that a small $P D X 1$ gene copy number per hepatocyte cannot efficiently activate the insulin promoter.
The importance of the transplantation site should also be noted. We were unable to effectively reduce plasma glucose levels when $2 \times 10^{7}$ transduced cells were injected directly into the portal vein of streptozotocin-induced diabetic rats. Although the cells formed islet-like structures with positive insulin staining, overall glucose homeostasis was not achieved even after 4 months (data not shown). The discrepancy between the rat and mouse models might be explained by species differences, the smaller amount of positive cells relative to the rat body weight, or an immune response to the gene product.

The forced expression of $P D X 1$ in primary hepatocytes induced expression of the following important components of the glucose-dependent mature insulin secretion cascade: (1) Insulin, Pcsk and Kcnj11; (2) numerous other genes related to pancreatic endocrine and exocrine function (glucagon, somatostatin, amylase, and pancreatic polypeptide); and (3) developmental-related transcription factors. Moreover, the approximately equal expression of both insulin genes in transduced cells supports the transdifferentiation process versus PDX1 acting primarily as an activator of the endogenous insulin gene. Although expression of albumin was significantly downregulated in PDXItransduced cells, it was still expressed, suggesting an incomplete transdifferentiation of these cells, at least in some of the cells or in the first 8 days after transduction.

The in vitro studies were done 8 to 10 days after transduction, the longest period over which we could keep the cells viable. The $P D X 1$-transduced hepatocytes were less responsive to glucose and secreted less insulin than native beta cells in vitro (RIA). At this time point, metabolic labelling and HPLC analyses failed to detect a proinsulin:insulin ratio. Apart from the technical problem, it is worth noting that the studies were conducted in cell culture after 10 days, while the in vivo effectiveness of these cells was established after 3 to 4 weeks. Although we demonstrated the existence of insulin by immunohistochemistry, radioimmunoassay and activity in vivo, we cannot rule out the possibility that in our model, proinsulin may have played a role in ameliorating in vivo glucose homeostasis. However, the cells secreted sufficient insulin to regulate glucose homeostasis over at least 8 weeks when transplanted in vivo. Bearing in mind that the effect reached significance only 3 weeks after transplantation, it is possible that the in vivo environment allows these engineered cells to further mature or differentiate into fully functional cells that are capable of lowering blood glucose levels. In support of this, equine lentiviral-mediated expression of $P D X 1$ turned fetal human progenitor liver cells into insulin-producing cells in about 3 weeks [30], while pancreatic non-endocrine cells transfected with $P D X 1$ expressed insulin and other beta cell specific genes in vitro, but were only able to actually secrete insulin after being 
transplanted in vivo [45]. Thus, a hepatic cell line (WB) that had been stably transfected with an activated form of $P D X 1$ and expressed many genes of endocrine pancreatic development showed a more mature islet expression profile after in vitro exposure to high glucose levels and even more after in vivo transplantation [46]. The hyperglycaemic in vivo environment and close contact with host cells may have contributed to the differentiation of cells into fully mature beta cells, although the exact mechanism is not yet exactly understood and not easy to establish.

Although hyperglycaemia was significantly improved in our PDX1-treated animals compared with controls, and occasional 12-h fasting measurements showed blood glucose levels in a normal range $(<5.5 \mathrm{mmol} / \mathrm{l})$, the PDX1-treated animals still manifested moderate hyperglycaemia under fed conditions. This may be due to the limited number of cells that could be injected, despite the efficient engraftment of the transplanted cells in this model of cell transplantation under the renal capsule.

Autotransplantation of genetically engineered hepatocytes avoids immune rejection and the concomitant side effects of lifelong immunosuppressive treatment. In the present study, we were unable to provide liver cell therapy by transplantation of genetically engineered hepatocytes via the portal vein as an alternative strategy to injecting an adenoviral $P D X 1$ vector. However, we believe that high expression of the $P D X 1$ gene in a limited number of cells may be sufficient to achieve normal insulin secretion and to allow correction of the metabolic disorder. Overall, our data demonstrate significant progress in the ex vivo gene delivery that is potentially applicable for type1 diabetes therapy.

Acknowledgements We thank S. Efrat (Sackler Faculty of Medicine, Tel Aviv University, Israel) for providing the beta cell line and the mouse insulin plasmid, and for his valuable help during this work. We thank N. Ruff and D. Beitner-Johnson at Biomed Editors for providing scientific editing. This research was partially supported by grants to E. Karnieli (by the Riva Foundation and the Linda Rose Diamond Fund). This work forms part of A. Fodor's PhD thesis. We wish to dedicate this work to the memory of our late $\mathrm{PhD}$ student, Alexander Bukhbinder.

Duality of interest None of the authors has a conflict of interest to declare in connection with this research.

\section{References}

1. de la Tour D, Halvorsen T, Demeterco C et al (2001) Beta-cell differentiation from a human pancreatic cell line in vitro and in vivo. Mol Endocrinol 15:476-483

2. Alam T, Sollinger HW (2002) Glucose-regulated insulin production in hepatocytes. Transplantation 74:1781-1787

3. Chen R, Meseck ML, Woo SL (2001) Auto-regulated hepatic insulin gene expression in type 1 diabetic rats. Mol Ther 3:584-590

4. Lu D, Tamemoto H, Shibata H, Saito I, Takeuchi T (1998) Regulatable production of insulin from primary-cultured hepato- cytes: insulin production is up-regulated by glucagon and cAMP and down-regulated by insulin. Gene Ther 5:888-895

5. Thule PM, Liu JM (2000) Regulated hepatic insulin gene therapy of STZ-diabetic rats. Gene Ther 7:1744-1752

6. Assady S, Maor G, Amit M, Itskovitz-Eldor J, Skorecki KL, Tzukerman M (2001) Insulin production by human embryonic stem cells. Diabetes 50:1691-1697

7. Soria B, Roche E, Berna G, Leon-Quinto T, Reig JA, Martin F (2000) Insulin-secreting cells derived from embryonic stem cells normalize glycemia in streptozotocin-induced diabetic mice. Diabetes 49:157-162

8. Lumelsky N, Blondel O, Laeng P, Velasco I, Ravin R, McKay R (2001) Differentiation of embryonic stem cells to insulin-secreting structures similar to pancreatic islets. Science 292:1389-1394

9. Yang L, Li S, Hatch $\mathrm{H}$ et al (2002) In vitro trans-differentiation of adult hepatic stem cells into pancreatic endocrine hormoneproducing cells. Proc Natl Acad Sci USA 99:8078-8083

10. Nakajima-Nagata N, Sakurai T, Mitaka T et al (2004) In vitro induction of adult hepatic progenitor cells into insulin-producing cells. Biochem Biophys Res Commun 318:625-630

11. Bonner-Weir S, Taneja M, Weir GC et al (2000) In vitro cultivation of human islets from expanded ductal tissue. Proc Natl Acad Sci USA 97:7999-8004

12. Ramiya VK, Maraist $M$, Arfors KE, Schatz DA, Peck AB, Cornelius JG (2000) Reversal of insulin-dependent diabetes using islets generated in vitro from pancreatic stem cells. Nat Med 6:278-282

13. Jonsson J, Carlsson L, Edlund T, Edlund H (1994) Insulinpromoter-factor 1 is required for pancreas development in mice. Nature 371:606-609

14. Offield MF, Jetton TL, Labosky PA et al (1996) PDX-1 is required for pancreatic outgrowth and differentiation of the rostral duodenum. Development 122:983-995

15. Stoffers DA, Zinkin NT, Stanojevic V, Clarke WL, Habener JF (1997) Pancreatic agenesis attributable to a single nucleotide deletion in the human IPF1 gene coding sequence. Nat Genet 15:106-110

16. Ahlgren U, Jonsson J, Jonsson L, Simu K, Edlund H (1998) Betacell-specific inactivation of the mouse $\operatorname{Ipf} 1 / \mathrm{Pdx} 1$ gene results in loss of the beta-cell phenotype and maturity onset diabetes. Genes Dev 12:1763-1768

17. Ohlsson H, Karlsson K, Edlund T (1993) IPF1, a homeodomaincontaining transactivator of the insulin gene. Embo J 12:42514259

18. Serup P, Petersen HV, Pedersen EE et al (1995) The homeodomain protein IPF-1/STF-1 is expressed in a subset of islet cells and promotes rat insulin 1 gene expression dependent on an intact E1 helix-loop-helix factor binding site. Biochem J 310(Pt 3):997-1003

19. Ritz-Laser B, Gauthier BR, Estreicher A et al (2003) Ectopic expression of the beta-cell specific transcription factor Pdx1 inhibits glucagon gene transcription. Diabetologia 46:810-821

20. Waeber G, Thompson N, Nicod P, Bonny C (1996) Transcriptional activation of the GLUT2 gene by the IPF-1/STF-1/IDX-1 homeobox factor. Mol Endocrinol 10:1327-1334

21. Watada H, Kajimoto Y, Umayahara Y et al (1996) The human glucokinase gene beta-cell-type promoter: an essential role of insulin promoter factor 1/PDX-1 in its activation in HIT-T15 cells. Diabetes 45:1478-1488

22. Brissova M, Shiota M, Nicholson WE et al (2002) Reduction in pancreatic transcription factor PDX-1 impairs glucose-stimulated insulin secretion. J Biol Chem 277:11225-11232

23. Gauthier BR, Brun T, Sarret EJ et al (2004) Oligonucleotide microarray analysis reveals PDX1 as an essential regulator of mitochondrial metabolism in rat islets. J Biol Chem 279:3112131130

24. Ferber S, Halkin A, Cohen $\mathrm{H}$ et al (2000) Pancreatic and duodenal homeobox gene 1 induces expression of insulin genes in liver and 
ameliorates streptozotocin-induced hyperglycemia. Nat Med 6:568-572

25. Ber I, Shternhall K, Perl S et al (2003) Functional, persistent, and extended liver to pancreas transdifferentiation. J Biol Chem 278:31950-31957

26. Naldini L, Blomer U, Gallay P et al (1996) In vivo gene delivery and stable transduction of nondividing cells by a lentiviral vector. Science 272:263-267

27. Nguyen TH, Oberholzer J, Birraux J, Majno P, Morel P, Trono D (2002) Highly efficient lentiviral vector-mediated transduction of nondividing, fully reimplantable primary hepatocytes. Mol Ther 6:199-209

28. Follenzi A, Sabatino G, Lombardo A, Boccaccio C, Naldini L (2002) Efficient gene delivery and targeted expression to hepatocytes in vivo by improved lentiviral vectors. Hum Gene Ther 13: 243-260

29. Sullivan DE, Dash S, Du H et al (1997) Liver-directed gene transfer in non-human primates. Hum Gene Ther 8:1195-1206

30. Zalzman M, Gupta S, Giri RK et al (2003) Reversal of hyperglycemia in mice by using human expandable insulinproducing cells differentiated from fetal liver progenitor cells. Proc Natl Acad Sci USA 100:7253-7258

31. Seglen PO (1976) Preparation of isolated rat liver cells. Methods Cell Biol 13:29-83

32. Dunn JC, Tompkins RG, Yarmush ML (1991) Long-term in vitro function of adult hepatocytes in a collagen sandwich configuration. Biotechnol Prog 7:237-245

33. Kreamer BL, Staecker JL, Sawada N, Sattler GL, Hsia MT, Pitot HC (1986) Use of a low-speed, iso-density percoll centrifugation method to increase the viability of isolated rat hepatocyte preparations. In Vitro Cell Dev Biol 22:201-211

34. Dull T, Zufferey R, Kelly M et al (1998) A third-generation lentivirus vector with a conditional packaging system. J Virol 72: 8463-8471

35. Salmon P, Kindler V, Ducrey O, Chapuis B, Zubler RH, Trono D (2000) High-level transgene expression in human hematopoietic progenitors and differentiated blood lineages after transduction with improved lentiviral vectors. Blood 96:3392-3398
36. Ory DS, Neugeboren BA, Mulligan RC (1996) A stable humanderived packaging cell line for production of high titer retrovirus/ vesicular stomatitis virus G pseudotypes. Proc Natl Acad Sci USA 93:11400-11406

37. Maor G, Rochwerger M, Segev Y, Phillip M (2002) Leptin acts as a growth factor on the chondrocytes of skeletal growth centers. J Bone Miner Res 17:1034-1043

38. Granner D, Pilkis S (1990) The genes of hepatic glucose metabolism. J Biol Chem 265:10173-10176

39. Malhi H, Irani AN, Rajvanshi P et al (2000) KATP channels regulate mitogenically induced proliferation in primary rat hepatocytes and human liver cell lines. Implications for liver growth control and potential therapeutic targeting. J Biol Chem 275:26050-26057

40. Miyatsuka T, Kaneto H, Kajimoto Y et al (2003) Ectopically expressed PDX-1 in liver initiates endocrine and exocrine pancreas differentiation but causes dysmorphogenesis. Biochem Biophys Res Commun 310:1017-1025

41. Rajagopal J, Anderson WJ, Kume S, Martinez OI, Melton DA (2003) Insulin staining of ES cell progeny from insulin uptake. Science 299:363

42. Kojima H, Fujimiya M, Matsumura K et al (2003) NeuroDbetacellulin gene therapy induces islet neogenesis in the liver and reverses diabetes in mice. Nat Med 9:596-603

43. Horb ME, Shen CN, Tosh D, Slack JM (2003) Experimental conversion of liver to pancreas. Curr Biol 13:105-115

44. Sapir T, Shternhall K, Meivar-Levy I et al (2005) From the cover: cell-replacement therapy for diabetes: generating functional insulin-producing tissue from adult human liver cells. Proc Natl Acad Sci USA 102:7964-7969

45. Zhao M, Amiel SA, Christie MR, Rela M, Heaton N, Huang GC (2005) Insulin-producing cells derived from human pancreatic non-endocrine cell cultures reverse streptozotocin-induced hyperglycaemia in mice. Diabetologia 48:2051-2061

46. Cao LZ, Tang DQ, Horb ME, Li SW, Yang LJ (2004) High glucose is necessary for complete maturation of Pdx1-VP16expressing hepatic cells into functional insulin-producing cells. Diabetes 53:3168-3178 